\title{
Determinants of Whistleblowing Intention: Evidence from the South
}

\section{Korean Government1}

Yongjin Chang, International University of Japan

Mark Wilding, University of Salford (Corresponding Author)2

Min Chul Shin, Board of Audit and Inspection of the Republic of Korea

\begin{abstract}
In 2001, the South Korean government passed the Anti-Corruption Act, which provides whistleblower protection in the public sector. The system of protections and rewards was strengthened in 2011 by the Act on the Protection of Public Interest Whistleblowers.

Although these laws ensure immunity — and even financial incentives - for whistleblowers, whistleblowing is still not a straightforward task. Based on a survey of 5706 public officials in central government, this study examines how a range of factors influence whistleblowing intention: attitude; knowledge; colleague support; organizational support; and protection against retaliation. A number of demographic variables, relating to gender; marital status; length of tenure; duty; and position type are used as controls. The results of the ordered probit regression analysis show all of the independent variables to have a significant positive effect on whistleblowing intention. However, colleague support and organizational support have the biggest effects, while perceived protection against retaliation has the smallest. This suggests that there is a need for future government efforts to build upon the available legal protections by focusing on creating a supportive culture among colleagues and in the organization more generally.
\end{abstract}

Key Words: Whistleblowing intention, South Korean government, Whistleblowing determinants, Ordered probit regression

\footnotetext{
1 This is an Accepted Manuscript of an article accepted for publication by Taylor \& Francis Group in Public Performance \& Management Review on 09/04/2017, available online http://www.tandfonline.com/loi/mpmr20 2 Contact: m.a.wilding@salford.ac.uk
} 


\section{Determinants of Whistleblowing Intention: Evidence from the South Korean Government}

Public sector whistleblowing has received considerable attention from researchers over the past three decades (Bashir, Khattak, Hanif \& Chonan, 2011; Buchan, 2005; Cho and Song, 2015; Miceli \& Near, 1988; Park \& Blenkinsopp, 2009; Rosenbloom \& Gong, 2013). In public administration, whistleblowers are a valuable means of exposing wrongdoing (such as fraud, waste, and abuse) that has already occurred or is presently taking place within public agencies. Whistleblowers have the advantage of possessing inside knowledge about their organizations and policy implementation processes as they can access information that is not readily available to government oversight systems or the public. Thus, the rigorous protection of whistleblowers serves to enhance government accountability and transparency, as well as public officials' freedom of speech (Rothschild, 2008).

Despite the benefits, the act of exposing wrongdoing within an organization is no easy task, and whistleblowers are often exposed to negative consequences such as demotion, dismissal and blacklisting (Cassematis \& Wortley, 2013; Chang et al., 2013; Miceli \& Near, 1985, 1992). The importance of whistleblower protection has been recognized at a global level and numerous countries have enacted legislation (Park, Blenkinsopp, Oktem \& Omurgonulsen, 2008). In particular, following OECD recommendations in 1998, the proportion of member states offering legal protection for whistleblowers increased from $44 \%$ in 2000 to $66 \%$ in 2009 (OECD, 2012a). More recently, progress has been made in the legal protections for whistleblowers among G20 countries including the US, Australia, China, France and India (Wolfe, Worth, Dreyfus \& Brown, 2014). South Korea (hereafter "Korea") has also introduced protections. Following the passage of the Anti-Corruption Act in 2001, Korea enacted the Act on the Protection of Public Interest Whistleblowers, one of the most comprehensive whistleblower protection laws in the world, in 2011 (Wolfe et al., 2014). 
Nevertheless, despite improved legal support in Korea, whistleblowing still appears to be detrimental to public officials' careers, with dismissal often following the decision to come forward (Chang et al., 2013).

Although public officials are cognizant of the difficulties of reporting wrongdoing, and many shoulder the risks and potential hardships, why do some public officials intend to blow the whistle while others do not? What factors influence their whistleblowing decisions? The present study examines these two questions in the Korean context. Using large-scale survey data, we analyze the extent to which there is a conducive environment in Korea by examining public officials' attitudes toward and knowledge of whistleblowing along with perceptions of organizational support and protection against retaliation, and testing their relationship to whistleblowing intention.

It is important to note that we examine intent, rather than actual whistleblowing behavior. Intent has been viewed as a predictor of behavior generally (Ajzen, 1991), and whistleblowing in particular (Park \& Blenkinsopp, 2009). While recognizing that the actual results for whistleblowing may differ from intent (Mesmer-Magnus \& Viswesvaran, 2005), we follow a number of previous studies in using intent as a proxy for behavior (Keil, Tiwana, Sainsbury \& Sneha, 2010; Park \& Blenkinsopp, 2009), due to the reported relationship with behavior and the challenges of obtaining large-scale data on infrequent behavior.

While there have been numerous attempts at explaining whistleblowing intention (Ahmad, Ismail \& Azmi, 2013; Cho \& Song, 2015 Keil et al., 2010; Mesmer-Magnus \& Viswesvaran, 2005; Park \& Blenkinsopp, 2009; Robinson, Robertson \& Curtis, 2012), the complexity of the issue and range of potential variables means that there are difficulties when attempting to apply over-arching theories to whistleblowing. As such, the present study draws upon a range of literature in order to formulate and test hypotheses relating to attitude toward and knowledge of whistleblowing, along with colleague and organizational support, and 
perceived protection against retaliation.

This study aims to contribute to the literature in three main ways. The first is to contribute to the international and cross-cultural research on whistleblowing by furthering knowledge about whistleblowing in the Korean context. Although there is a growing international literature on whistleblowing (Hwang, Staley, Te Chen \& Lan, 2008; Keenan, 2007; Zhang, Chiu \& Wei, 2009), it is still the case that less is known about the whistleblowing intention of government employees outside of the West. The Korean central government is a suitable case for investigation due to the introduction of policies and sustained efforts at implementation. Indeed, there have been ongoing attempts to change attitudes toward whistleblowing, along with improving related knowledge and organizational support and protection for whistleblowers (ACRC, 2016). Yet, the Korean government continues to face difficulties in its fight against corruption (Transparency International, 2016). Thus, there is a need to examine the whistleblowing intention of public sector employees within this context. The second aim is to contribute to theory development on whistleblowing through testing a number of hypotheses. Finally, this study seeks to make recommendations for government organizations that will help to create a more conducive environment for reporting wrongdoing.

The remainder of this study is composed as follows. Whistleblowing in the Korean context is discussed in the next part, along with hypotheses based upon the literature about predictors of whistleblowing intention. After outlining the study methods, the results of the statistical analysis of survey data collected from 5706 central government public officials are presented. In the final part, conclusions are drawn and suggestions outlined for improving whistleblower protection.

\section{Theoretical Background}

\section{Whistleblowing and the Korean Context}


Whistleblowing has been famously defined as "disclosure by organization members (former or current) of illegal, immoral, and illegitimate practices under the control of their employers, to persons or organizations that may be able to effect action" (Near \& Miceli, 1985, p. 4). Though originally developed in relation to the private sector, this definition has been widely applied in public sector research (Robinson et al., 2012; Tavakoli, Keenan \& CranjakKaranovic, 2003). According to this perspective, whistleblowing is a process that involves "the whistleblower, the whistleblowing act or complaint, the party to whom the complaint is made, and the organization against which the complaint is lodged" (Near \& Miceli, 1985, p. 2).

In the Korean context, it is important to note the distinctive political environment, where factors relating to government, economics, labor market, and culture may have constrained whistleblowing. There have been successive waves of administrative and regulatory reforms since democratization in the late 1980s. However, the limits of liberalization in the face of strong state traditions have been emphasized, and there has not been a dramatic reduction in the influence of elected politicians over the bureaucracy since democratization (Park \& Wilding, 2016).

Close working relationships between politicians and the chaebol (diversified conglomerates) continue and have included presidential pardons of senior chaebol figures convicted of corruption related crimes (The Economist, 2010). Most recently, former president Park Geun-hye was arrested in March 2017 following impeachment for using her business connections to pressure companies to give millions of dollars to the non-profit foundations of her confidante Choi Soon-sil (BBC News, 2016). It remains to be seen whether this will affect attitudes to corruption in the longer term. However, the benefits that the chaebol bring to Korean society in terms of employment and financial investment mean that individuals may hesitate to challenge their interests. 
While public sector jobs have long been coveted in Korea due the status and jobsecurity offered, a key development since the 1997 Asian financial crisis has been labor market deregulation. Approximately one third of Korean jobs now have 'non-standard' employment conditions meaning that there is no security of tenure, and less wages and benefits than for standard employees (Cooke \& Brown, 2015). Thus, public sector jobs continue to be desirable, as seen through the competitive examination system. This raises questions about the extent to which public employees would risk their employment to report corruption.

In terms of cultural context, Korea differs from the West due to its traditional emphasis on Confucianism and hierarchical collectivism (Wilding, Chae \& Jang, 2014; Yang \& Torneo, 2016). Confucianism stresses love, harmony, kindness, and benevolence, underpinned by respect for seniors (according to age and position) (Kee, 2008). In terms of hierarchical collectivism, Hofstede, Hofstede and Minkov (2010) point to group loyalties and uncertainty avoidance among the Korean people as key characteristics. Both Confucianism and hierarchical collectivism may be important for whistleblowing as it has been argued that in contemporary Korea, the traditional loyalty between sovereign and subject has been reinterpreted as organizational loyalty (Park, Rehg \& Lee, 2005), and that there has been a tendency to view whistleblowers as betrayers (Chang, Park \& Min, 2011).

Although it was not until 2001 that the Anti-Corruption Act was passed, a number of early public sector whistleblowing cases greatly contributed to controlling corruption, promoting budgetary efficiency, guaranteeing people's right to know, and advancing human rights (Park, 2008). Still, despite benefiting Korean society, the absence of appropriate legal protections meant that whistleblowers were harshly treated in the form of job loss and even suicide resulting from social pressure and retaliation (Shin, 2006). The first instance of public whistleblowing since 1953 took place in 1990 when Lee Moon-ok, a public official of the 
Board of Audit and Inspection, spoke out about the role of illegal lobbies in the halting of investigations into chaebol branches. His whistleblowing exposed the undesirable and illegal cooperation between government and the chaebol. Nevertheless, Lee was placed under arrest for four days after he stepped forward, on the grounds that he had disclosed confidential information relating to his duty, and he also lost his job. In 1996, Lee won all resulting lawsuits, and was found not guilty of disclosing confidential information. After his five-year legal battle, he came back to government employment in a different role, before retiring in 1999 (Huh, 2010).

A second case involved Lieutenant Lee Jee-mun of the Korean Army who exposed irregularities concerning absentee voting on his military base during the $14^{\text {th }}$ National Congressional Election on March 22, 1992. According to Lieutenant Lee, soldiers were forced to participate in both open and proxy voting, and to attend a special lecture on the theme of supporting ruling party candidates. After blowing the whistle, Lieutenant Lee was detained and demoted to the rank of private. Following a three-year lawsuit, he was cleared of spreading disinformation but prevented from returning to Samsung Group, where he had obtained an entry level position before undertaking mandatory military service (Lee, J.M., 2003).

According to J.Y. Lee (2003), there were 32 significant whistleblowing cases during the 1990s in diverse organizations and across a number of fields, including cases involving the Audit Board, the military, the police, local elections, social welfare facilities, the Bank of Korea, private schools, Incheon Airport, and various government contracts. The lack of sufficient legal protection meant that most whistleblowers lost their jobs. Interestingly, a 1999 study into perceptions and attitude toward whistleblowing among 389 public officials working for Seoul City government found that over half of respondents would whistleblow if they uncovered corruption and the problem persisted after their efforts to fix it (Lee, 1999). 
However, it was still the case that $47.4 \%$ responded that whistleblowing outside the organization was undesirable, and 51.8\% thought that it boosted distrust among organizational members. 3

Due to the number of negative outcomes for whistleblowers, civil society organizations persistently requested the enactment of legal protection. Faced with campaigning by Citizen Solidarity for the Anti-Corruption Act, a group of 38 civil society organizations, the National Assembly finally passed the Anti-Corruption Act, which was signed into law by President Kim Dae-jung on June 28, 2001 (Park, 2004; Lee, J.Y., 2003). The Act incorporated whistleblowing provisions including a requirement for public officials to report cases of corruption, and set forth guidelines for whistleblowing and investigation processes, protection from retaliation, compensation and reward, and establishment of the Anti-Corruption Agency (Committee), which was "the first legal agency that was solely dedicated to anticorruption function in Korean history" (Choi, 2009, p. 200).

Since its enactment, the law has been amended twice (2005 and 2008), and further legal provision was made in 2011, in the form of the Act on the Protection of Public Interest Whistleblowers. The 2011 law aims both to protect and financially reward public and private sector whistleblowers. Observed wrongdoings should be reported to the Anti-Corruption and Civil Rights Commission (ACRC), which fulfills the functions of both anti-corruption commission and ombudsman. Between 2002 and 2013, the ACRC received information on 28,246 reported cases of wrongdoing. In the 220 cases which were deemed to be instances of

\footnotetext{
3 The questions asked were: "Even though you tried to fix the problem of corruption in your organization and the corruption practice still continues, do you blow the whistle outside of the organization?" (Responses: Strongly yes: $3.7 \%$; Yes: $53.1 \%$; No: $43.2 \%$; Not at all: $0 \%$ ). The questions relating to attitude were, firstly: "What do you think about public officials blowing the whistle outside of the organization?" (Responses: Desirable 52.6\%; Not Desirable: 47.4\%); secondly: "If you think about whistleblowing, what kind of image first comes to mind?" (Responses: Efficient tool to get rid of corruption: 13.4\%; Improve ethics and democracy in organization: 14.4\%; Increase right to know of citizens: $2.1 \%$; Spoil line of command: $4.9 \%$; Boost distrust among organizational members: 51.8\%; Decrease public trust of government (public organizations) by exposing low quality of information: $13.4 \%)$.
} 
corruption, the ACRC recovered a total of US\$60.3 million, while whistleblowers received US\$6.2 million in financial compensation (Wolfe et al., 2014). The rewards ranged from 4\% to $20 \%$ of the recovered government revenues, with the upper limit increasing to $30 \%$ in October 2015 to reinforce the incentives for reporting wrongdoing (ACRC, 2016). During 2002-2013, there were 181 requests for whistleblower protection and $36 \%$ of these were granted (Wolfe et al., 2014).

Even though the government has attempted to shape a better legal environment for whistleblowers, and the law seems somewhat effective at protecting whistleblowers and exposing corruption, Korea still needs to address shortcomings in the law. According to a recent assessment of worldwide whistleblowing protection provisions, the Korean public sector whistleblower protection law presents unclear rules in three areas: circumstances where seeking external reporting channels are justified, internal disclosure procedures, and protections for anonymous reporting (Wolfe et al., 2014). In the Corruption Perceptions Index, Korea still had a low score of 53 in 2016, compared to 74 for the US, while the UK received a score of 81, and Sweden 88 (Transparency International, 2017). The number of public officials who breached the code of conduct has also risen from 1,089 in 2009 to 1,965 in 2014 (ACRC, 2016). The available evidence thus suggests that there is a need to improve ethical standards, as well as the use of whistleblowing more specifically as an effective tool in the fight against corruption.

\section{Predictors of Public Sector Whistleblowing Intention in Korea}

As discussed above, changes to the legal environment since the enactment of the AntiCorruption Act in 2001 have established whistleblowing processes along with a system of rewards/ compensation and mechanisms for whistleblower protection in the Korean public sector. The breadth of these changes suggests that there is a need to examine the extent to 
which attitude toward whistleblowing, knowledge of whistleblowing processes, perceived protection against retaliation, organizational support, and colleague support impact upon whistleblowing intention. The Act has been in operation for some time, and there has been increased publicity about protection for whistleblowers. We therefore expect that public officials will have knowledge of and a favorable attitude toward whistleblowing, along with a positive perception of support and protection available from their organization and colleagues.

Attitude toward whistleblowing. Attitude toward a behavior means "the degree to which a person has a favorable or unfavorable evaluation or appraisal of the behavior in question" (Ajzen, 1991, p. 188). It is important to measure attitude toward whistleblowing as an independent variable, as a supportive attitude is not the same as whistleblowing intention and there is not always a strong link between the two, particularly if there are few resources and opportunities available and there are perceived negative social pressures (Ajzen, 1991). Still, generally, as a person's attitude toward a behavior becomes more favorable, intention to perform the behavior becomes stronger. As such, a number of studies have analyzed attitude as a predictor of whistleblowing intention (Park \& Blenkinsopp, 2009; Park et al., 2005; Richardson, Wang \& Hall, 2012; Trongmateerut \& Sweeney, 2012). More specifically, attitude has been found to have a positive effect on internal whistleblowing intention in Korea (Park \& Blenkinsopp, 2009). We, therefore, hypothesize as follows:

Hypothesis 1: Positive attitude toward whistleblowing increases whistleblowing intention among public officials.

Knowledge of whistleblowing process. As noted above, the Anti-Corruption Act 
outlines the overall public sector whistleblowing process, including who can and who should blow the whistle, where they can report, and how to proceed. The law supports internal whistleblowing only; public officials should only report to the ACRC, investigative agencies, or the Board of Audit and Inspection of Korea. If external reports are made (i.e., to the press or non-profit organizations), the whistleblower will not receive legal protection. Under the law, all informers should identify themselves to the agency where they file the report by submitting their personal information, including name and affiliation. Importantly, the law also outlines protection which is available against retaliation and how to obtain financial compensation.

Knowledge of whistleblowing channels and processes might be an important predictor of whistleblowing intention. Even though the government has enacted a range of whistleblower protections, if people lack knowledge about appropriate channels and the whistleblowing procedure, they will be hesitant to come forward (Near \& Miceli, 1985). Similarly, Cho and Song (2015) found whistleblowing training to have a positive effect on whistleblowing intention. Therefore, the current study hypothesizes that:

Hypothesis 2: Greater knowledge about appropriate channels and procedures of whistleblowing increases whistleblowing intention among public officials.

Colleague and organizational support for whistleblowing. Members of an organization can perceive organizational support by fair and transparent operation of dissent channels, whistleblowing education programs, and leaders, middle managers, or colleagues' positive responses after previous whistleblowing incidents (Miceli, Near, Rehg \& Van Scotter, 2012; Miceli, 1995; Sims \& Keenan, 1998; Thoroughgood, Hunter \& Sawyer, 2011). Research has found organizational climate to create perceptions and shape the behavior of 
members in various work situations (Thoroughgood et al., 2011). More specifically, MesmerMagnus and Viswesvaran (2005) find that organizational climate for whistleblowing is related to both whistleblowing intention and actual whistleblowing. However, the social desirability of whistleblowing has been subject to debate. For example, Cruise (2002) sees whistleblowing as dysfunctional and points to the long-lasting nature of the detrimental effects for organizations. In the East-Asian context, employees have traditionally been reluctant to report wrongdoing due to the perception of whistleblowers as betrayers or informants (Park et al., 2005). In this regard, support from organizations and colleagues may reduce the potential psychological costs, and thereby have a positive influence on whistleblowing intention. We hypothesize as follows:

Hypothesis 3: Public officials are more likely to intend to blow the whistle when they perceive there to be sufficient organizational support.

Hypothesis 4: Public officials are more likely to intend to blow the whistle when they perceive there to be sufficient colleague support.

Perceived protection against retaliation. Many whistleblowers suffer from various forms of retaliation after their actions. Examples include social isolation, verbal and physical violence, close monitoring of work, demotion, no promotion, dismissal, counter accusations, and blacklisting (Cassematis \& Wortley, 2013; Chang et al., 2013). Rothschild (2008) finds that fear of retaliation was the most important reason underlying the decision not to blow the whistle. Mesmer-Magnus and Viswesvaran (2005) also suggest that fear of retaliation was negatively related to whistleblowing intention. This may be particularly important in the Korean context where the practice of whistleblowing has had terrible consequences for some 
whistleblowers. In several case studies conducted by Chang et al. (2013), whistleblowers not only operated in an unsupportive environment, but were also identified and experienced retaliation including losing their jobs. As such, potential whistleblowers may face significant financial and psychological costs. The hostile responses are seemingly rooted in collectivism, which sees organizational goals as more important than individuals' goals, and values "loyalty, harmony, cooperation, unity, conformity, and the unquestioning acceptance of norms, attitudes, and values in an organization" (Park et al., 2005, p. 391). It is not surprising if this environment seriously discourages potential whistleblowers despite improvements in the Korean whistleblower protection law. Therefore, this study hypothesizes that:

Hypothesis 5: Perceptions that whistleblowers are strongly protected against possible retaliation are associated with increased whistleblowing intention among public employees.

\section{Control Variables}

While attitude toward and knowledge of whistleblowing are important, along with organizational support and protection, there is also a need to address personal variables, as some demographic groups may be more likely to blow the whistle than others. Researchers have found various demographic predictors to influence whistleblowing intention. More specifically, gender, age, income, education, and marital status have been shown to have a significant influence (Keil et al., 2010; Mesmer-Magnus \& Viswesvaran, 2005; Miceli \& Near, 1988, Sims \& Keenan, 1998; Zhang et al., 2009). However, the results have often varied considerably. For example, on the one hand, studies by Keil et al. (2010) and MesmerMagnus and Viswesvaran (2005) suggest that women are more likely to blow the whistle than men. On the other hand, Miceli and Near (1988), Sims and Keenan (1999), and Bashir et al. (2011) claim that men are more likely to decide to blow the whistle than women. In a similar 
vein, age is a significant variable for Bashir et al. (2011), Keil et al. (2010), and Zhang et al. (2009), but Sims and Keenan (1999) find age to have little influence on whistleblowing decision. The present study includes gender, marital status, tenure, duty and position. We anticipate that gender may be of particular relevance. Even when occupying nominally the same roles, women are often treated differently than men (Franke, Crown \& Spake, 1997), and may face harsher retaliation for whistleblowing (Rehg, Miceli, Near \& Van Scotter, 2008). Given Korean women's disadvantage in the labor market (Cooke \& Brown, 2015), they may be less willing to put their career at risk in order to report wrongdoing.

\section{Method}

\section{Data}

The survey was designed and administered by the Audit and Inspection Research Institute to examine how changes to organizational environment influence organizational behavior, to learn about public officials' conception of corruption, and to develop new monitoring and oversight policies. The survey was web-based, and ran from August 1-24, 2012. There have been no major whistleblowing cases up to the time of writing that could be seen to affect the relevance of the results. Park Geun-hye's impeachment may eventually impact upon public officials' views on corruption in Korea, but it is not yet clear what shape this might take and it will take time for the dust to settle.

All public officials working in central government were sent an email inviting voluntary participation, and ensuring anonymity of identity and confidential treatment of survey data. This yielded a total of 5,706 responses, equivalent to $3.7 \%$ of the country's approximately 154,000 central government employees (OECD, 2012b). It is important to note that the Audit and Inspection Research Institute has a central and privileged role in examining attitudes to whistleblowing among Korean public officials, but this of course does not mean 
that it is neutral. Thus, the possibility that the nature of the Institute may have attracted some respondents but put off others cannot be ruled out, nor can the possibility that this might have influenced response bias in favor of whistleblowing.

\section{Measures}

The dependent variable is whistleblowing intention (WBI), as outlined in the statement "I intend to blow the whistle if I find corruption in my organization."4 Respondents were asked to choose an option from four ordered responses (Strongly disagree; Disagree; Agree; Strongly agree). Using these ordinal responses means that we are not able to measure the distance between the responses (for example, the difference between strongly agree and agree). There is much debate about the benefits of a neutral response option (i.e., neither agree nor disagree), with some researchers recommending its inclusion in order to reduce response bias (Weijters, Cabooter \& Schillewaert, 2010). However, by eliminating the midpoint response, we attempted to stimulate respondents' cognitive processes to decide on optimal answers (Krosnick, Narayan \& Smith, 1996). A related issue is the number of response alternatives. While reliability and validity have been found to improve as the number of response alternatives increases, it has been suggested that the optimum number of options is between four and seven (Lozano, García-Cueto \& Muñiz, 2008).

The main explanatory variables were measured using single items as follows: attitude toward whistleblowing (“In general, I support public officials' whistleblowing”); knowledge of whistleblowing ("I know appropriate procedures and have sufficient knowledge about whistleblowing"); perceived protection against retaliation ("I think public officials are properly protected from possible retaliation when they become whistleblowers");

\footnotetext{
4 Based upon the Anti-Corruption Act, public officials should only report corruption which violates the law to the ACRC, investigative agencies, or the Board of Audit and Inspection of Korea. Thus, responses were not concerned with other forms of wrongdoing (which violate social norms but not the law for example), nor reporting to supervisors, press, or the public.
} 
organizational support (“My organization supports whistleblowing”); and colleague support (“My colleagues support whistleblowing”). While there are occasions where multiple item measures are desirable, the aim was to provide a concise web-based survey by shortening the number of questions and thus, boosting response rates, which are relatively low in online surveys (Christophersen \& Konradt, 2011).

Demographic characteristics were captured by five variables. Gender (1: female, 0: otherwise) and marital status (1: married, 0: otherwise) were entered dichotomously. Tenure was measured in years, then entered in eight categories (1-5 years, 6-10, 11-15, 16-20, 21-25, 26-30, 31-35, 36 or above). Additional controls include duty and position held by public employee. Duty was entered using eight categories (Regulation, general service, tax, procurement and property management, planning/budgeting \& research, human resource management, evaluation and audit, other). Finally, position was entered using six categories (Regular government service, special service, positions by political appointees, skilled \& technical service, temporary contract, other).

\section{Sample}

The Audit and Inspection Research Institute did not target public officials with specific characteristics, which means that the sample is more representative of some groups than others. As can be seen in Table 1, there were more male (76.6\%) than female respondents (23.4\%). In the population of central government public officials, the respective percentages were $68.9 \%$ and $31.1 \%$ (MOPAS, 2012). When it comes to length of service, there was a relatively even spread, with the most frequent responses being 16-20 years of service (20.7\%), 21-25 years of service (18.8\%), and 6-10 years of service (17.7\%). The great majority of respondents $(84.3 \%)$ were married, which reflects national trends (Frejka, Jones $\&$ Sardon, 2010). A wide range of job duties were found among respondents, with the most 
frequent responses being general service $(30.1 \%)$, followed by planning, budgeting, and research (15.4\%). The survey was broadly representative in terms of position type, with the exception of special service employees, who at $12.0 \%$ were overrepresented $(1.0 \%$ in the population), and skilled and technical service employees, who at $7.1 \%$ were underrepresented (24.9\% in the population) (MOPAS, 2012).

\section{Analytical Strategy}

The analysis involved three steps. The first involved using factor association to explore the association of each factor with WBI in order to generate descriptive statistics to better understand the sample characteristics (the relationships between the predictors on the one hand and WBI on the other). In the second step, ordered probit models were fitted to predict public officials' WBI. Ordered probit analysis was used as the dependent variable takes the form of an ordered category, and it allows us to measure the WBI of respondents with particular characteristics (attitude, knowledge, colleague support, etc.).

The model is shown below:

$$
\begin{aligned}
& \text { WBI }_{i}=\beta_{1} * \text { ATTITUDE }+\beta_{2} * \text { KNOWLEDGE }+\beta_{3} * \text { ORGANIZATIONAL SUPPORT }+\beta_{4} * \\
& \text { COLLEAGUE SUPPORT }+\beta_{5} * \text { PROTECTION }+\beta_{6} * \text { FEMALE }+\beta_{7} * \text { MARRIED }+ \\
& \beta_{8} * \text { TENURE }+\beta_{9} * \text { DUTY }+\beta_{10} * \text { POSITION }+\varepsilon_{i}
\end{aligned}
$$

where $\varepsilon$ is normally distributed (Liao, 1994).

The dependent ordered variable $\mathrm{WBI}_{\mathrm{i}}$ of an observation $i$ takes the values of 1, 2, 3 and 4 in accordance with the $k$ cut-off points (threshold parameters) as follows: 


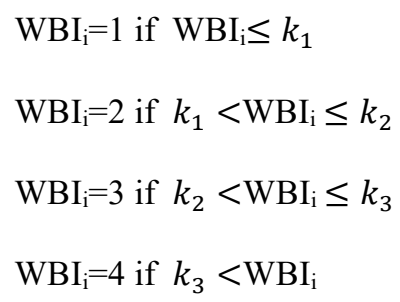

In the third step, average marginal effects in the ordered probit model were investigated. This strategy allowed the examination of the discrete change in predicted probability of each level of WBI for each of the values of the predictors. In particular, outcomes of high levels of WBI were focused on $(\mathrm{WBI}=3$ and $\mathrm{WBI}=4)$. For marginal effects estimation, average marginal effects (AMEs) were used. While marginal effects at the means (MEM) are widely used (Williams, 2012), MEM has the limitation that it uses some values that a real person could not have, such as being $23.4 \%$ female or $84.3 \%$ married. In contrast, AME involves computing the marginal effects for every case in the sample, rather than simply using the means.

\section{Results}

\section{Factor Association with Whistleblowing Intention}

Factor association with WBI is summarized in Table 1. Among the total 5,706 respondents, $76.9 \%$ chose the two high categories of WBI (WBI=1=strongly disagree, $2.4 \%$, $\mathrm{WBI}=2=$ disagree $, 20.7 \%, \mathrm{WBI}=3=$ agree, $57.8 \%$ and $\mathrm{WBI}=4=$ strongly agree, $19.1 \%$ ). As far as main factors are concerned, answer option 3 (i.e., agree) was the most frequent choice among the total sample, accounting for an approximate range of 54-59\% of responses for all but one of the variables. Perceived protection against retaliation was the exception as option 2 outnumbered option 3 (41.4\% compared to $34.7 \%)$. This can be interpreted as meaning that the majority of respondents had high perceived levels of attitude, knowledge, colleague and organizational support for whistleblowing, but did not feel that adequate levels of protection 
against retaliation were in place. It can also be seen that the main factors have positive relationships with the higher WBI responses; with each additional level of attitude, knowledge, colleague and organizational support, and perceived protection against retaliation, the proportion choosing response $3(\mathrm{WBI}=3)$ increased dramatically. The largest rise was seen in colleague support, which jumped from $15.7 \%$ to $80.1 \%$ for $\mathrm{WBI}=3$ (from colleague support=1 to colleague support=3), followed by organizational support, which increased from $23.5 \%$ to $79.4 \%$ (from organizational support=1 to organizational support=3). This suggests that colleague and organizational support play an important role in influencing the level of WBI. A similar relationship was also observed for response 4; the highest degrees (i.e., 4 out of 4) of attitude, knowledge, colleague and organizational support, and protection against retaliation were associated with the greatest shares of the strongly positive WBI, ranging from $61.4 \%(\mathrm{knowledge}=4)$ to $83.2 \%$ (protection against retaliation $=4)$.

In terms of control variables, male respondents showed higher rates (by $2 \%$ for $\mathrm{WBI}=3$ and $10.5 \%$ for $\mathrm{WBI}=4$ respectively), indicating stronger $\mathrm{WBI}$ by male compared to female public employees. Being married seemed to have a negligible difference in the two highest WBI categories, as differences of less than 3\% were observed. Factor association also tells us little about the remaining control variables. When it comes to tenure, for example, officials with 36 years or more experience were the most likely to select $\mathrm{WBI}=3$, while those with 31-35 years' experience were least likely (a difference of 15.5\%). However, for WBI=4, this situation was reversed; officials with $31-35$ years' experience were $12 \%$ more likely to select the highest category of WBI when compared to colleagues with 36 years or more experience. In order to investigate the relationships in more depth, we conducted an ordered probit regression analysis.

Table 1 to Feature Here

\section{Ordered Probit Models}


The results of the probit models are displayed in table 2 in hierarchical order. Each additional predictor in the subsequent models improved model fit. For instance, model 6 shows a better fit than model $5\left[\chi^{2}(21 \mathrm{df})=66, \mathrm{p}<0.01\right]$. The statistically significant threshold parameters (cutoff 1 , cutoff 2 and cutoff 3 , all $\mathrm{p}<0.01$ ) in each model indicate that the four response categories are different from each other, establishing the need to proceed to ordered probit modeling. The final model explains approximately $30 \%$ of the variation in WBI. The largest proportion of variation was attributable to attitude followed by colleague support $\left(\mathrm{R}^{2}=0.139\right.$ and $\Delta \mathrm{R}^{2}=0.078$, respectively). Organizational support and knowledge also made up approximately $10-13 \%$ of the total variation in WBI (see recalculated $\mathrm{R}^{2}$ in Table 2 ), while perceived level of protection and demographic variables hardly contributed to the variance.

\section{Table 2 to Feature Here}

In order to focus on the relationship with high levels of WBI, the next step was to examine the marginal effects. As displayed in Table 3, attitude, knowledge, colleague support, organizational support, and protection against retaliation have strong positive effects on the choice of the highest category, $\mathrm{WBI}=4(\beta=0.228,0.276,0.698,0.504,0.197$, all $\mathrm{p}<0.01)$. Females showed a lower propensity to choose the strongest WBI response than males. Service of five years or more also had a negative effect on choosing WBI=4. However, tenure of 20 years or more was not statistically significant at $5 \%$, suggesting that respondents with tenure length of over 20 years are similar to those with a short tenure of 1-5 years when it comes to choosing $\mathrm{WBI}=4$. In contrast, positions generally had a positive relationship with $\mathrm{WBI}=4$, although not all positions were statistically significant. Marital status and job duty were not found to be good predictors $(\mathrm{p}>0.05)$.

While ordered probit estimates reveal the average effect of each predictor, average marginal effects show a discrete change in the expected probability of choosing response 
category $4(\mathrm{WBI}=4)$. The largest changes were for colleague support and organizational support; a one-point increase in colleague support and organizational support raises the probability of choosing $\mathrm{WBI}=4$ by approximately $12.5 \%$ and $9 \%$ respectively. Other main factors had relatively less influence on choosing the highest category. Each additional level of attitude and knowledge is associated with $4.1 \%$ and $4.9 \%$ increased likelihood of choosing $\mathrm{WBI}=4$. For each higher level of perceived protection, individuals were $3.3 \%$ less likely to select $\mathrm{WBI}=2$ and $3.5 \%$ more likely to report $\mathrm{WBI}=4$. Female public officials, however, are negatively associated with $\mathrm{WBI}=4$; they were $3.4 \%$ less likely to report $\mathrm{WBI}=4$ than men. Those with 6-20 years of service were also 2-3\% less inclined to choose WBI=4 than those whose tenure was 1-5 years. In terms of position, political appointees were $8.1 \%$ more likely to select the highest category of WBI, followed by skilled and technical services (4.1\%) and special services $(2.3 \%)$, when compared to the regular government service position.

\section{Table 3 to Feature Here}

\section{Discussion and Conclusions}

The results reveal several important findings. First of all, the descriptive statistics suggest that public officials in Korean central government have a positive attitude toward whistleblowing, and consider themselves to have sufficient knowledge of whistleblowing procedures and appropriate support for whistleblowing from both colleagues and organizations. The positive relationship of attitude, knowledge, colleague support, organizational support, and protection against retaliation with WBI confirms hypotheses 1-5.

The analysis of marginal effects, while supporting the role of attitude and knowledge, sheds light on the importance of colleague and organizational support. Indeed, colleague and organizational support were the first and second strongest predictors of $\mathrm{WBI}=4$ respectively. 
WBI increased with higher reported levels of colleague and organizational support, which emphasizes the importance of government responsibility in encouraging and supporting whistleblowing. This responsibility goes beyond a rule based approach to the creation of a supportive atmosphere. Perceived protection against retaliation, with the least influence among the main variables, plays less of a role than in previous studies (Rothschild, 2008). This is particularly interesting given the Korean context and history of severe consequences (Lee, J.M., 2003; Lee, J.Y., 2003).

When taken together with the findings for organizational and colleague support, it may be that the benefits of formal protection are perceived to be limited if faced with potentially hostile responses from colleagues and the wider organization. Even when whistleblowers have not been dismissed, forced to resign, or blacklisted, they have faced difficulties such as being excluded from organizational opinion channels, having work withheld, and being isolated from their colleagues (Chang et al., 2013; Jeon, 2003). Consequently, most whistleblowers have felt isolated and faced emotional and physical health problems.

Turning to the control variables, female public officials reported lower WBI. There has been considerable debate in the literature about who is more likely to whistleblow: women (Keil et al., 2010; Mesmer-Magnus \& Viswesvaran, 2005) or men (Bashir et al., 2011; Miceli \& Near, 1988; Sims \& Keenan, 1999). The results in the present study may be understood by women's relative lack of power in the Korean workplace where they feel more vulnerable in terms of employment security and are more likely to want to avoid controversy and unnecessary attention. The other main group with low WBI were those with between six and 20 years of service. Strong public sector job security and a desire among public employees to maintain this appears to hinder whistleblowing activities in Korea, particularly for employees who may feel locked in to a particular career path and still have a considerable 
number of years before retirement.

Political appointees, special service, and skilled and technical service employees all reported higher levels of WBI than those in regular government service. In the case of political appointees, this may be influenced by their relatively powerful positions within the government hierarchy, where their skills are in demand. However, all of these employee types are more likely to work alone or in small teams, meaning that they may be less concerned about potentially negative responses from colleagues.

The lack of longitudinal data and studies with similar questions on whistleblowing in Korea means that it is difficult to make comparisons. However, a greater proportion of respondents both indicated their intention to whistleblow and saw whistleblowing outside the organization as desirable than in Lee's (1999) study of Seoul City government. Although caution is needed in the absence of a directly comparable study, the findings do support research which has found attitude and knowledge of whistleblowing processes to have positive effects on WBI (Cho \& Song, 2015; Near \& Miceli, 1985; Park \& Blenkinsopp, 2009). Rather than seeing whistleblowing as having negative effects (Cruise, 2002), public officials have shown their intention to come forward, but organizational and colleague support is clearly influential. This highlights the continued importance of collectivism, through loyalty and seeking a harmonious working climate. More practically, it points to the limits of legislation and toward the need for initiatives which can help create a supportive organizational culture.

It is important to note that the present study has some limitations. First, due to using data collected for government purposes, we were unable to include a wider range of variables relating to WBI. For example, questions about the perceived seriousness of the wrongdoing, types of wrongdoing, and status of wrongdoers may have helped to paint a more nuanced picture, as would distinguishing between awareness of protection and awareness of 
colleagues who actually received protection. In addition, as responses are based upon employee perceptions, they do not offer objective indicators of support, protection, and knowledge. Still, the data does offer a valuable insight into employee perceptions, and there are significant correlations with WBI.

As the Audit and Inspection Research Institute did not target particular characteristics among public officials, it could be suggested that those who associate greater risks with whistleblowing were less likely to respond. A recommendation for future research is to target particular respondent characteristics, for example through stratified sampling. More generally, future studies could conduct qualitative interviews with whistleblowers in order to investigate actual whistleblowing, rather than intent.

\section{Implications and Recommendations}

On the one hand, the results suggest that the Anti-Corruption Act and ACRC policy implementation have been somewhat effective in publicizing the importance of whistleblowing and raising knowledge of the available mechanisms. On the other hand, researchers have criticized ACRC's limited independence and investigative power, the narrow range of protections offered, poor enforcement of ACRC decisions, and the limited number of formal whistleblowing channels (Lee, J.Y., 2003; Park, 2008). This was confirmed in the data as the majority of responses for protection against retaliation were in the lower half of the scale. This can be understood in the context of insufficient protection stemming from unclear rules in external, internal and anonymous reporting (Wolfe et al., 2014). The lower levels of perceived protection may indicate that Korean public employees are not sure about what protection is available against internal disclosure procedures. Also, protections for anonymous reporting by public officials are not in place in Korea. This calls for a stronger role from the Korean government in establishing clear rules about appropriate reporting 
channels in favor of protecting whistleblowers against retaliation before promoting the improved rules to government employees.

The findings represent a challenge to the Korean government's efforts to encourage employees to report corruption. There have been great improvements in the legal protection available. While essential, this is only part of the story and is unlikely to succeed without the support of colleagues and the wider organization. Moreover, discrimination against women and employee insecurity relating to fear of losing their livelihood in a competitive labor market are not issues which can be addressed overnight, particularly in light of women's position in Korea's polarized labor market (Choi \& Park, 2014; Cooke \& Brown, 2015).

However, there is more that the Korean government can do to create a supportive environment in which employees feel comfortable blowing the whistle. As such, this study recommends that the Korean government should focus its efforts on training and promotional materials, which use empathy toolkits and outline the importance of supporting colleagues who report corruption. These efforts would need to be informed by awareness of the role of gender, tenure length, and position type in relation to WBI, in order to help shape an environment where all employees benefit from colleague and organizational support and do not feel that their employment would be jeopardized by whistleblowing. Engaging more employees in this way would help to improve WBI, and also have the broader positive effects of increasing transparency, fairness, and ultimately, increasing trust (Shim \& Park, 2016); goals which are shared by whistleblowers. 


\section{References}

Ahmad, S. A., Ismail, I. S., \& Azmi, N. A. (2013). Exploring internal auditors' whistleblowing intentions towards corporate fraud: A prosocial behaviour perspective. In F. L. Gaol, S. Kadry, M. Taylor \& S. L. Pak (Eds.), Recent trends in social behavioural sciences (pp. 463-467). London: CRC Press.

Ajzen, I. (1991). The theory of planned behavior. Organizational Behavior and Human Decision Processes, 50, 179-211.

Anti-Corruption and Civil Rights Commission (ACRC) (2016). News and publications. Retrieved from http://www.acrc.go.kr/eng/board.do?command=searchDetail\&method=searchList\&m enuId $=0205$

Banisar, D. (2006). Whistleblowing international standards and developments. Paper presented at the Primera Conferencia International Sobre Corruption y Transparencia, Ciudad de Mexico, Mexico.

Bashir, S., Khattak, H. R., Hanif, A., \& Chohan, S. N. (2011). Whistle-blowing in public sector organizations: Evidence from Pakistan. American Review of Public Administration, 41(3), 285-296.

Buchan, H.F. (2005). Ethical decision making in the public accounting profession: An extension of Ajzen's theory of planned behavior. Journal of Business Ethics, 61, 165181.

BBC News (2016). South Korea's presidential scandal. Retrieved from http://www.bbc.co.uk/news/world-asia-37971085

Cassematis, P. G., \& Wortley, R. (2013). Prediction of whistleblowing or non-reporting observation: The role of personal and situational factors. Journal of Business Ethics, $117(3), 615-634$. 
Chang, Y., Park S., Min, J., Kim, K., Kang, Y. \& Kim, M. (2013). People who dream a society no corruption: Case studies of whistleblowing in Korea. Seoul: CM Press.

Chang, Y., Park, S. E., \& Min, J.-H. (2011). Study of factors to make whistleblowing effective: A case study of three cases of whistleblowing in South Korea. Korean Journal of Public Administration, 49(4): 111-144.

Cho, Y. J., \& Song, H. J. (2015). Determinants of whistleblowing within government agencies. Public Personnel Management, 44(4), 450-472.

Choi, J. W. (2009). Institutional structures and effectiveness of anticorruption agencies: A comparative analysis of South Korea and Hong Kong. Asian Journal of Political Science, 17(2), 195-214.

Choi, S., \& Park, C. O. (2014). Glass Ceiling in Korean civil service analyzing barriers to women's career advancement in the Korean Government. Public Personnel Management, 43(1), 118-139.

Christophersen, T., \& Konradt, U. (2011). Reliability, validity, and sensitivity of a single-item measure of online store usability. International Journal of Human-Computer Studies, 69(4), 269-280.

Cooke, F. L., \& Brown, R. (2015). The regulation of non-standard forms of employment in China, Japan and the Republic of Korea. Geneva: International Labour Organization.

Cruise, P. L. (2002). Are there virtues in whistleblowing? Perspectives from health care organizations. Public Administration Quarterly, 25(4), 413-435.

Franke, G. R., Crown, D. F., \& Spake, D. F. (1997). Gender differences in ethical perceptions of business practices: A social role theory perspective. Journal of Applied Psychology, $82,920-934$.

Frejka, T., Jones, G. W., \& Sardon, J. P. (2010). East Asian childbearing patterns and policy developments. Population and Development Review, 36(3), 579-606. 
Hofstede, G., Hofstede, G. J., \& Minkov, M. (2010). Cultures and organizations: Software of the mind (3rd ed.). Columbus, OH: McGraw-Hill.

Hwang, D., Staley, B., Te Chen, Y., \& Lan, J. S. (2008). Confucian culture and whistleblowing by professional accountants: An exploratory study. Managerial Auditing Journal, 23(5), 504-526.

Huh, W. J. (2010). Lee Moon Ok, the conscious man who woke Korea up. Pressian, May 11. Retrieved from http://www.pressian.com/article/article.asp?article_num=60100511004259

Jeon, C. W. (2003). Research on intensity factors of retaliations against whistleblowing. Korean Policy Science Review, 7(1), 125-149.

Kee, T. S. (2008). Influences of Confucianism on Korean corporate culture. Asian Profile, $36(1), 9-24$.

Keenan, J. P. (2007). Comparing Chinese and American managers on whistleblowing. Employee Responsibilities and Rights Journal, 19(2), 85-94.

Keil, M., Tiwana, A., Sainsbury, R., \& Sneha, S. (2010). Toward a theory of whistleblowing intentions: A benefit-to-cost differential perspective. Decision Sciences, 41(4), 787812.

Krosnick, J. A., Narayan, S., \& Smith, W. R. (1996). Satisficing in surveys: Initial evidence. New Directions for Evaluation, 1996(70), 29-44.

Lee, J. M. (1999). Research on perception and attitude toward whistleblowing of public organizations: Focused on public officials and citizens in Seoul City (Unpublished master's thesis). Korea University, Seoul.

Lee, J. M. (2003). Whistle for public interest, whistleblowing. Seoul: Korean Public Administration Database Center.

Lee, J. Y. (2003). Problems and improvement of anti-corruption law. Chung Ang Journal of 
Legal Studies, 5(1), 169-193.

Liao, T. F. (1994). Interpreting probability models: Logit, probit, and other generalized linear models. London: Sage.

Lozano, L. M., García-Cueto, E., Muñiz, J. (2008). Effect of the number of response categories on the reliability and validity of rating scales. Methodology: European Journal of Research Methods for the Behavioral and Social Sciences, 4(2), 73-79.

Mesmer-Magnus, J. R., \& Viswesvaran, C. (2005). Whistleblowing in organizations: An examination of correlates of whistleblowing intentions, actions, and retaliation. Journal of Business Ethics, 62(3), 277-297.

Miceli, M. P., \& Near, J. P. (1988). Individual and situational correlates of whistle-blowing. Personnel Psychology, 41(2), 267-281.

Miceli, M. P., \& Near, J. P. (1992). Blowing the whistle: The organizational and legal implications for companies and employees. New York, NY: Lexington Books.

Miceli, M. P., Near, J. P., Rehg, M. T., \& Van Scotter, J. R. (2012). Predicting employee reactions to perceived organizational wrongdoing: Demoralization, justice, proactive personality, and whistle-blowing. Human Relations, 65(8), 923-954.

MOPAS (Ministry of Public Administration and Security). (2012). 2011 Statistics on public officials in central government. Seoul: MOPAS.

Near, J. P. \& Miceli, M. P. (1985). Organizational dissidence: The case of whistle-blowing. Journal of Business Ethics, 4, 1-16.

OECD (2012a). Whistleblower protection: Encouraging reporting. Paris: OECD.

OECD (2012b). Human resources management country profiles: Korea. Paris: OECD.

Park, H., Blenkinsopp, J., Oktem, M. K., \& Omurgonulsen, U. (2008). Cultural orientation and attitudes toward different forms of whistleblowing: A comparison of South Korea, Turkey, and the UK. Journal of Business Ethics, 82(4), 929-939. 
Park, H., \& Blenkinsopp, J. (2009). Whistleblowing as planned behavior: A survey of South Korean police officers. Journal of Business Ethics, 85(4), 545-556.

Park, H., Rehg, M. T., \& Lee, D. (2005). The influence of Confucian ethics and collectivism on whistleblowing intentions: A study of South Korean public employees. Journal of Business Ethics, 58(4), 387-403.

Park, K. C. (2008). Current state and issues of whistleblower protection system. Legal Studies, 18(3), 151-190.

Park, S. H., \& Wilding, M. (2016). The politics of government reform in Korea: From tripartite to bipartite politicization. Administration \& Society, 48(9), 1059-1084.

Rehg, M. T., Miceli, M. P., Near, J. P., \& Van Scotter, J. R. (2008). Antecedents and outcomes of retaliation against whistleblowers: Gender differences and power relationships. Organization Science, 19, 221-240.

Richardson, B. K., Wang, Z., \& Hall, C. A. (2012). Blowing the whistle against Greek hazing: The theory of reasoned action as a framework for reporting intentions. Communication Studies, 63(2), 172-193.

Robinson, S. N., Robertson, J. C., \& Curtis, M. B. (2012). The effects of contextual and wrongdoing attributes on organizational employees' whistleblowing intentions following fraud. Journal of Business Ethics, 106(2), 213-227.

Rosenbloom, D. H., \& Gong, T. (2013). Coproducing “clean” collaborative governance: Examples from the United States and China. Public Performance \& Management Review, 36(4), 544561.

Rothschild, J. (2008). Freedom of speech denied, dignity assaulted: What the whistleblowers experience in the US. Current Sociology, 56(6), 884-903.

Shim, J., \& Park, J.-H. (2016). Public participation and trust in government: The case of the Korean Financial Regulatory Agency. Public Performance \& Management Review, 
$40(1), 1-22$.

Shin, K. S. (2006). I exposed injustice, but I fight against this society where is insensitive to justice. Seoul: Book Publishing Participatory Society.

Sims, R. L. \& Keenan, J. P. (1998). Predictors of external whistleblowing: Organizational and intrapersonal variables. Journal of Business Ethics, 17, 411-421.

Sims, R. L., \& Keenan, J. P. (1999). A cross-cultural comparison of managers' whistleblowing tendencies. International Journal of Value-Based Management, 12(2), $137-151$.

Tavakoli, A. A., Keenan, J. P., \& Cranjak-Karanovic, B. (2003). Culture and whistleblowing an empirical study of Croatian and United States managers utilizing Hofstede's cultural dimensions. Journal of Business Ethics, 43(1-2), 49-64.

The Economist (2010). South Korea's industrial giants: Return of the overlord. The Economist. March 31. Retrieved from http://www.economist.com/node/15816702

Thoroughgood, C. N., Hunter, S. T., \& Sawyer, K. B. (2011). Bad apples, bad barrels, and broken followers? An empirical examination of contextual influences on follower perceptions and reactions to aversive leadership. Journal of Business Ethics, 100(4), 647-672.

Transparency International (2017). Corruption perceptions index 2016. Retrieved from http://www.transparency.org/news/feature/corruption_perceptions_index_2016 Trongmateerut, P., \& Sweeney, J. T. (2013). The influence of subjective norms on whistleblowing: A cross-cultural investigation. Journal of Business Ethics, 112(3), 437-451.

Weijters, B., Cabooter, E., \& Schillewaert, N. (2010). The effect of rating scale format on response styles: The number of response categories and response category labels. International Journal of Research in Marketing, 27(3), 236-247.

Wilding, M., Chae, K., \& Jang, J. (2014). Emotional labor in Korean local government: 
Testing the consequences of situational factors and emotional dissonance. Public Performance \& Management Review, 38(2), 316-336.

Williams, R. (2012). Using the margins command to estimate and interpret adjusted predictions and marginal effects. Stata Journal, 12, 308-331.

Wolfe, S., Worth, M., Dreyfus, S., \& Brown, A. (2014). Whistleblower Protection Laws in G20 Countries: Priorities for Action. Retrieved from http://www.griffith.edu.au/_data/assets/pdf_file/0010/647542/FINAL__ Whistleblower-Protection-Laws-in-G20-Countries-Priorities-for_-Action.pdf

Yang, S. B., \& Torneo, A. R. (2016). Government performance management and evaluation in South Korea: History and current practices. Public Performance \& Management Review, 39(2), 279-296.

Zhang, J., Chiu, R., \& Wei, L. (2009). Decision-making process of internal whistleblowing behavior in China: Empirical evidence and implications. Journal of Business Ethics, $88(1), 25-41$. 
Table 1. Factor Association with Whistleblowing Intention (WBI)

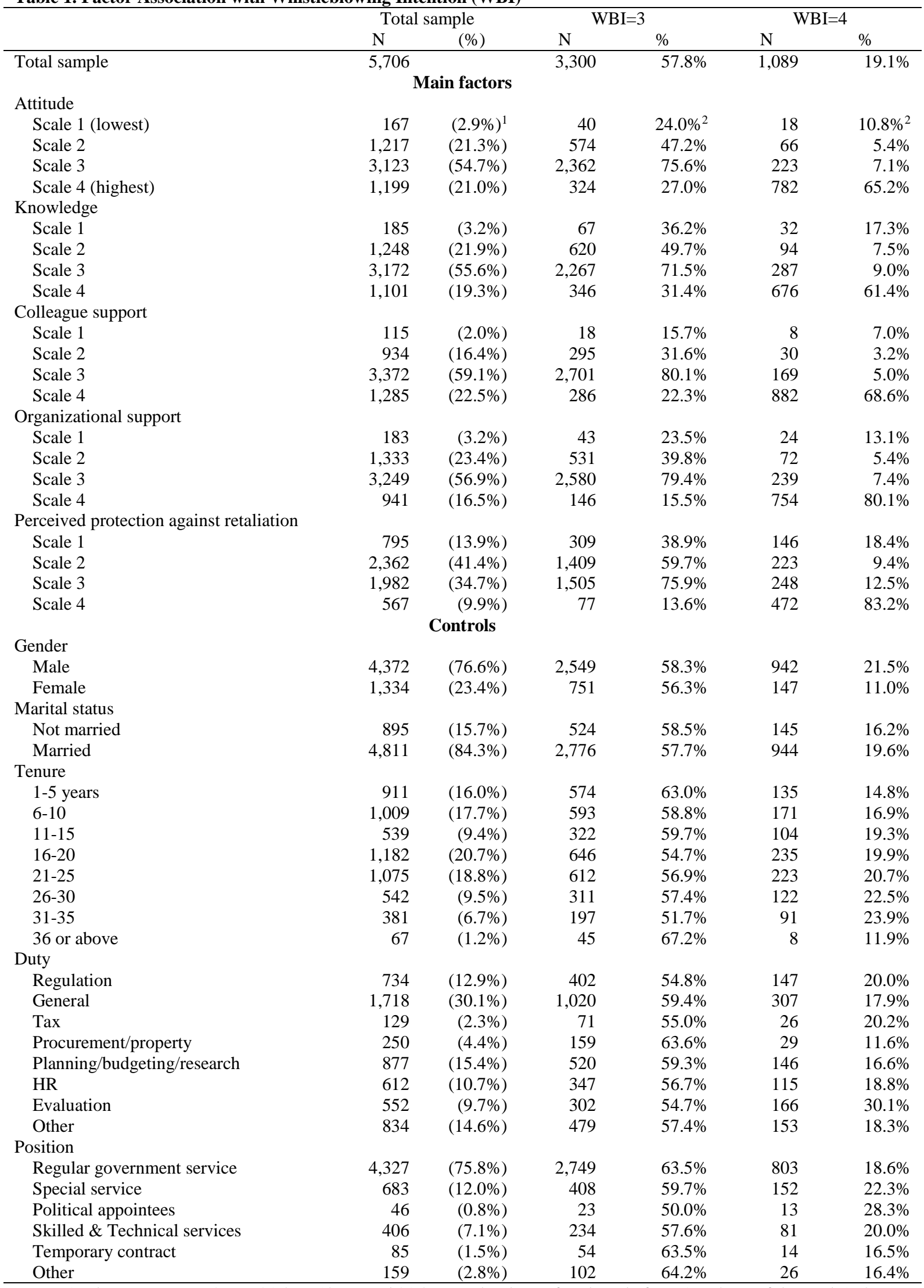

Notes: 1 . The percentages, $2.9 \%, 21.3 \%, 54.7 \%$ and $21.0 \%$ are the share of each scale from 1 to 4 out of the total 5,706 responses. 2 . The proportion, $24 \%$ is calculated by 40 divided by 167 (i.e., the share of participants who chose WBI=3 along with Scale 1 of the attitude variable). 
Table 2. Ordered Probit Models

\begin{tabular}{|c|c|c|c|c|c|c|}
\hline & 1 & 2 & 3 & 4 & 5 & $6^{3}$ \\
\hline Attitude & $\begin{array}{c}0.889 * * \\
(0.023)\end{array}$ & $\begin{array}{c}0.754 * * \\
(0.024)\end{array}$ & $\begin{array}{c}0.313 * * \\
(0.028)\end{array}$ & $\begin{array}{c}0.239 * * \\
(0.029)\end{array}$ & $\begin{array}{c}0.230 * * \\
(0.029)\end{array}$ & $\begin{array}{c}0.228 * * \\
(0.029)\end{array}$ \\
\hline Knowledge & & $\begin{array}{c}0.489 * * \\
(0.023)\end{array}$ & $\begin{array}{c}0.452 * * \\
(0.024)\end{array}$ & $\begin{array}{c}0.336^{* *} \\
(0.025)\end{array}$ & $\begin{array}{c}0.276^{* *} \\
(0.026)\end{array}$ & $\begin{array}{c}0.276^{* *} \\
(0.027)\end{array}$ \\
\hline Colleague support & & & $\begin{array}{c}0.915 * * \\
(0.031)\end{array}$ & $\begin{array}{c}0.683 * * \\
(0.033)\end{array}$ & $\begin{array}{c}0.704 * * \\
(0.033)\end{array}$ & $\begin{array}{c}0.698 * * \\
(0.033)\end{array}$ \\
\hline Organizational support & & & & $\begin{array}{c}0.579 * * \\
(0.030)\end{array}$ & $\begin{array}{c}0.498 * * \\
(0.032)\end{array}$ & $\begin{array}{c}0.504 * * \\
(0.032)\end{array}$ \\
\hline Perceived protection against retaliation & & & & & $\begin{array}{c}0.199 * * \\
(0.023)\end{array}$ & $\begin{array}{c}0.197 * * \\
(0.023)\end{array}$ \\
\hline Cutoff 1 & $\begin{array}{c}0.296 * * \\
(0.068)\end{array}$ & $\begin{array}{c}1.230 * * \\
(0.082)\end{array}$ & $\begin{array}{c}2.342 * * \\
(0.093)\end{array}$ & $\begin{array}{c}2.627 * * \\
(0.096)\end{array}$ & $\begin{array}{c}2.699 * * \\
(0.098)\end{array}$ & $\begin{array}{c}2.602 * * \\
(0.118)\end{array}$ \\
\hline Cutoff 2 & $\begin{array}{c}1.736 * * \\
(0.065)\end{array}$ & $\begin{array}{c}2.714 * * \\
(0.081)\end{array}$ & $\begin{array}{c}3.989 * * \\
(0.095)\end{array}$ & $\begin{array}{c}4.358^{* *} \\
(0.099)\end{array}$ & $\begin{array}{c}4.450 * * \\
(0.100)\end{array}$ & $\begin{array}{c}4.368^{* *} \\
(0.119)\end{array}$ \\
\hline Cutoff 3 & $\begin{array}{c}3.652 * * \\
(0.074)\end{array}$ & $\begin{array}{c}4.731 * * \\
(0.092)\end{array}$ & $\begin{array}{c}6.200 * * \\
(0.109)\end{array}$ & $\begin{array}{c}6.646^{* *} \\
(0.114) \\
\end{array}$ & $\begin{array}{c}6.751 * * \\
(0.116)\end{array}$ & $\begin{array}{c}6.688 * * \\
(0.133)\end{array}$ \\
\hline-2 loglikelihood & 10305 & 9846 & 8913 & 8540 & 8467 & 8401 \\
\hline McFadden's R ${ }^{2}$ & 0.139 & 0.177 & 0.255 & 0.286 & 0.293 & 0.298 \\
\hline$\Delta \mathrm{R}^{2}$ & & $0.038^{1}$ & 0.078 & 0.031 & 0.007 & 0.005 \\
\hline $\begin{array}{l}\text { Recalculated } \mathrm{R}^{2} \\
* \mathrm{p}<0.05, * * \mathrm{p}<0.01\end{array}$ & $47 \%^{2}$ & $13 \%$ & $26 \%$ & $10 \%$ & $2 \%$ & $2 \%$ \\
\hline
\end{tabular}


Table 3. Ordered Probit Overall Estimates and Marginal Effects

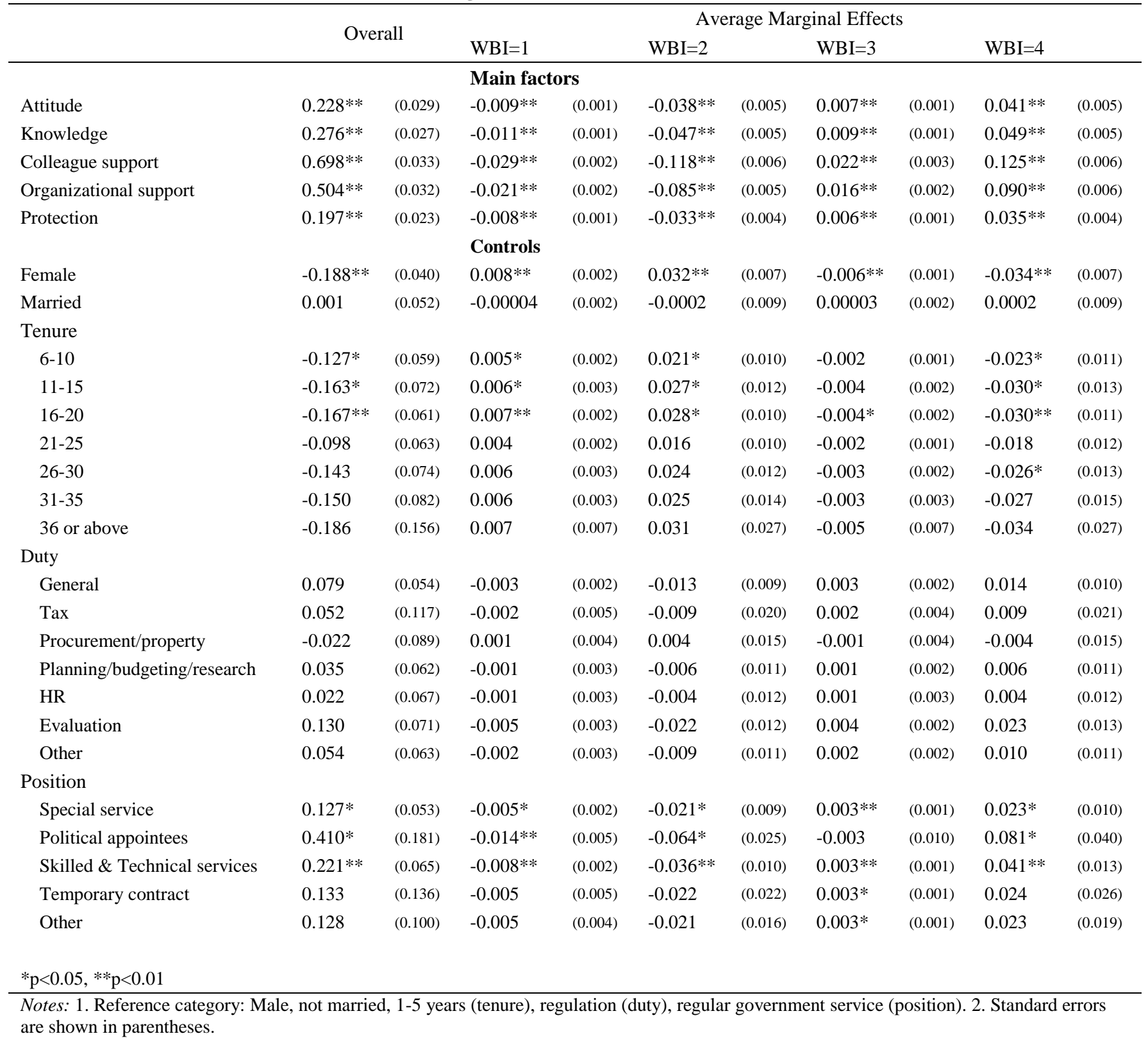

